\title{
БЮДЖЕТИРОВАНИЕ КАК ИНСТРУМЕНТ ФИНАНСОВОГО ПЛАНИРОВАНИЯ ОРГАНИЗАЦИИ
}

\author{
(c) 2018 Гогачева Ольга Владимировна \\ кандидат экономических наук, доцент \\ Московский государственный медико-стоматологический университет имени А.И. Евдокимова \\ 127473, г. Москва, ул. Делегатская, д. 20, стр. 1 \\ Email: kaf.ek.a@yandex.ru
}

В статье финансовая структура организации при бюджетировании разделена по центрам финансовой ответственности, что позволяет контролировать движение денежных средств и отслеживать источники доходной и расходной части бюджетов. Также рассмотрены этапы планирования главного бюджета и составлены бюджеты прибыли и расходов от основной деятельности, налогов и сборов, прочих возможных доходов, клиентской базы предприятия в зависимости от категорий прогнозов.

Ключевые слова: центры финансовой ответственности, этапы формирования бюджетирования; главный, операционные и финансовые бюджеты.

Финансовое планирование представляет собой важную часть в достижении экономического успеха. В России, зачастую, многие предприятия финансовому планированию отводят второстепенную роль. Они считают, что главной задачей их деятельности является занять определенное место на рынке, без обдумывания плана на долгосрочную перспективу. В результате при наступлении кризисной ситуации руководство оказывается не готово к быстрому реагированию. Такое отношение к бизнесу приводит к потерям возможных выгод, а иногда и к полному финансовому краху. Нацеленность на улучшение финансовых показателей, в частности прибыли, является движущей силой развития финансового планирования.

При этом задачей бюджетирования является определение показателей, оказывающих наибольшее влияние на финансовый результат, а также факторов, от которых зависит изменение этих показателей. За счет бюджетов компания начинает планировать свою деятельность, создавать критерии контроля и улучшать их взаимосвязь.

Для внедрения бюджетирования потребуется большой запас времени и средств. Это одна из причин, по которой большинство руководителей игнорирует данный метод финансового управления. Также стоит отметить, что составление бюджетов теряет смысл, если происходит быстрая смена экономической обстановки, так как показатели, которые были заложены в план бюджета, перестают быть актуальными.
При построении системы бюджетирования целесообразно создание новой организационной структуры управления предприятием, определяющей права и ответственность руководителей подразделений. Построение бюджетов структурных подразделений начинается с анализа организационной структуры предприятия. На первом этапе создается перечень видов деятельности, производства и услуг, анализируется их степень обособленности. На втором этапе определяются те подразделения, которые не приносят доход, и где распределяются доходы, расходы и затраты по подразделением и проводится оценка управляемых и не управляемых затрат. Последний этап выявляет подразделения, которые должны отвечать за движение средств на предприятии.

Финансовая структура при бюджетировании разделяет организацию по центрам финансовой ответственности (ЦФО). Это дает возможность контролировать движение денежных средств и отслеживать источники доходной и расходной части бюджетов. Данный способ детализации дает возможность объективно диагностировать состояние предприятия. Для анализа принято различать следующие ЦФО (табл. 1) [1].

Оценка деятельности ЦФО производится по показателям финансовой деятельности. Эффективность оценивается в результате сравнения плановых и фактических значений показателей, при этом руководитель ЦФО должен принять меры, которые должны быть направлены на повышение уровня эффективности деятельности 
Таблица 1. Виды центров финансовой ответственности

\begin{tabular}{|l|l|}
\hline \multicolumn{1}{|c|}{ ЦФО } & \multicolumn{1}{c|}{ Характеристика } \\
\hline $\begin{array}{l}\text { Центры прибыли - подразделения } \\
\text { приносящие прибыль }\end{array}$ & $\begin{array}{l}\text { Менеджеры данного подразделения наиболее рационально распре- } \\
\text { деляют доходы и расходы, особое внимание уделяют рискам, так как } \\
\text { убытки будут покрываться из бюджета подразделения, в котором эти } \\
\text { убытки имели место быть }\end{array}$ \\
\hline Центры инвестиций & $\begin{array}{l}\text { Данные подразделения внедряются на новые рынки, которые в силу } \\
\text { объективных причин не достигли самоокупаемости и финансируются } \\
\text { из бюджета предприятия }\end{array}$ \\
\hline $\begin{array}{l}\text { Центры обслуживания центров } \\
\text { прибыли и инвестиций }\end{array}$ & $\begin{array}{l}\text { Формируются из потребностей других ЦФО, и финансируется за счет } \\
\text { центров прибыли }\end{array}$ \\
\hline
\end{tabular}

ЦФО. Структура предприятия формируется и закрепляется в Положении о финансовой структуpe.

Для планирования деятельности руководители ЦФО должны составить бюджет своего подразделения и сформировать детальный отчет по затратам и результатам деятельности. Все управляющие подразделений несут ответственность за принятые ими решения и показатели.

При составлении основного бюджета меняется и адаптируется ценовая и кредитная политика предприятия, происходит оценка рисков, анализируются вероятные последствия принятых управлением решений.

Бюджетирование требует строгой регламентации и создания внутренних нормативных документов. Их нужно приводить к соответствию с бюджетным циклом. При формировании полного плана деятельности предприятия создается главный бюджет.

На первом этапе распределяются уровни раскрытия состава бюджета, т.е. выстраивается определенный уровень раскрытия подробной информации о бюджете того или иного подразделения.

На втором этапе определяются ответственные лица, которые будут ответственны за свою часть главного бюджета. Необходимо отметить, что существуют такие расходы, за которые несет ответственность общее руководство предприятия (например, расходы на интернет).

Контроль осуществляется не только на основе предоставляемой подразделением отчетности, но и сопоставления фактически достигнутых показателей с плановыми. В соответствующих положениях отражается уровень допустимых отклонений. На основе этих отклонений есть возможность составить мотивационную часть, но это следует делать в случае сложившейся и состоявшейся на предприятии политики финансового планирования за счет системы бюджетирования. Следует отметить, что вероятность искажения показателей мало вероятна в связи с тем, что все бюджеты взаимозависимы и на главном бюджете можно будет отследить, несоответствие показателей (например, размер прибыли, не соответствует уплаченному налогу на прибыль) [2].

Сопоставление плановых бюджетов с отчетами об их выполнении дает возможность влиять на показатели, которые имеют серьезное негативное (с точки зрения доходов) влияние. Как было сказано выше, сопоставляются бюджеты других подразделений и выявляются причины этих отклонений.

Если итоговые показатели по подразделениям неудовлетворительны, выявляются пути улучшения финансовой ситуации и дается оценка возможных изменений.

Анализ проводится в денежном эквиваленте в сопоставлении с плановыми показателями всех и (или) любых элементов имущества и источников их формирования, а также выявляются факторы, влияющие на их изменения.

Все руководители своих подразделений проводят оценку работы своих подразделений, руководитель предприятия оценивает работу предприятия в целом. За счет исследования отклонений выявляется ответственное лицо, которое несет ответственность за неудовлетворительные результаты, а также наоборот, которое повышает степень притока денежных средств, и выявляются причины как положительных, так и отрицательных отклонений.

От периодичности проведения сбора отчетов подразделений, зависит рентабельность самого финансового планирования за счет бюджетирования. Для расчета одних показателей (бюджета клиентской базы) источник информации формируются в течение года (за счет показателей прошлого года и заключенных действующих договоров, можно составить прогноз клиентской 
базы), а где-то можно сформировать на основе имеющихся данных (затраты на покупку сырья, позволяют в короткий срок создать бюджет затрат на производство). Необходимо регламентировать сроки сбора информации по каждому из бюджетов.

Инвентаризация отчетов очень сильно облегчает эту задачу. Это помогает использовать полученную информацию для незамедлительной корректировки планов.

Процесс бюджетирования необходимо стандартизировать за счет положений, методик, отчеты по которым позволят систематизировать подход к управлению финансами компании и закрепить бюджетную политику в разделе управленческой учетной политики.

Для удобства нужно составлять электронные таблицы, с целью автоматизации заполнения соответствующих показателей в главном бюджете. Результатом данного процесса станет упрощение создания главного бюджета с целью предоставления его руководству предприятия.

Главный бюджет разрабатывается на основе свода показателей производственно-финансового плана (табл. 2) и плана потребности в экономических ресурсах (табл. 3) [3].

Указанные расходы соответствуют предполагаемому объёму производства и отражают динамику развития производства на планируемый период.

Затем составляются бюджеты (прибыли и расходов от основной деятельности, налогов и сборов, прочих возможных доходов, клиентской базы предприятия) в зависимости от «категорий прогнозов»: умеренный прогноз - безубыточное производство без увеличения долга по задолженности перед кредиторами; оптимальный прогноз - производство, при котором будет оплачено 50\% долга; оптимистичный прогноз производство, при котором долг предприятия будет погашен полностью (табл. 4-6) [4].

На основе выше изложенного, можно сделать следующие выводы.

Бюджетирование позволяет повысить обоснованность и эффективность принимаемых управленческих решений. Его задача заключается в обоснованности планирования с целью контроля за текущей деятельностью предприятия.

Взаимосвязь между бюджетированием и финансовым планированием заключается в том, что бюджетирование является одним из способов финансового планирования на предприятии. Разница по отношению к другим способам, заключается в том, что все показатели в бюджетах взаимозависимы.

Главный бюджет формируется на основе операционного бюджета и системы взаимозависимых бюджетов. Стоит отметить, что есть возможность создания специальных бюджетов.

Операционные бюджеты включают в себя планируемые показатели на предстоящий период. Они формируются из прогноза продаж и необходимого объема производства.

Финансовые бюджеты отражают финансовое состояние предприятия, либо финансовые показатели деятельности. Они формируются за счет источников операционных бюджетов, сводя всю информацию в единое целое, либо раскрывая состав показателей бюджета. Главный бюджет составляется на основе уровней, которые учитывают ограничения, определяющие результат

Таблица 2. Планируемый объём продаж

\begin{tabular}{|l|c|c|c|c|}
\hline \multirow{2}{*}{ Наименование организации-покупателя } & \multicolumn{4}{|c|}{ Период } \\
\cline { 2 - 5 } & $\begin{array}{c}1 \text { кв. 20_г., } \\
\text { тыс. pyб. }\end{array}$ & $\begin{array}{c}2 \text { кв. 20_г., } \\
\text { тыс. pyб. }\end{array}$ & $\begin{array}{c}3 \text { кв. 20_г., } \\
\text { тыс. pуб. }\end{array}$ & $\begin{array}{c}4 \text { кв. 20_г., } \\
\text { тыс. pуб. }\end{array}$ \\
\hline & & & & \\
\hline & & & & \\
\hline Итого поступления от реализации, с НДС & & & & \\
\hline
\end{tabular}

Таблица 3. План потребности в экономических ресурсах

\begin{tabular}{|l|c|c|c|c|}
\hline \multirow{2}{*}{ Наименование ресурсы } & \multicolumn{4}{|c|}{ Период } \\
\cline { 2 - 5 } & $\begin{array}{c}1 \text { кв. 20_г., } \\
\text { тыс. руб. }\end{array}$ & $\begin{array}{c}2 \text { кв. 20_г., } \\
\text { тыс. руб. }\end{array}$ & $\begin{array}{c}\text { 3 кв. 20_г., } \\
\text { тыс. руб. }\end{array}$ & $\begin{array}{c}4 \text { кв. 20_г., } \\
\text { тыс. руб. }\end{array}$ \\
\hline & & & & \\
\hline Итого расходов & & & & \\
\hline
\end{tabular}


Таблицุа 4. Прогноз прибыли и расходов от основной деятельности

\begin{tabular}{|l|l|l|l|}
\hline & $\begin{array}{c}\text { Умеренный } \\
\text { прогно3 }\end{array}$ & $\begin{array}{c}\text { Оптимальный } \\
\text { прогно3 }\end{array}$ & $\begin{array}{c}\text { Оптимистический } \\
\text { прогноз }\end{array}$ \\
\hline Поступления от реализации, с НДС & & & \\
\hline НДС & & & \\
\hline Выручка от реализации продукции (без НДС) & & & \\
\hline Расходы & & & \\
\hline Прибыль до налогообложения & & & \\
\hline Налог на прибыль, 20\% & & & \\
\hline Чистая прибыль & & & \\
\hline
\end{tabular}

Таблица 5. Прогноз налогов и отчислений

\begin{tabular}{|l|c|c|c|}
\hline & $\begin{array}{c}\text { Умеренный } \\
\text { прогноз }\end{array}$ & $\begin{array}{c}\text { Оптимальный } \\
\text { прогноз }\end{array}$ & $\begin{array}{c}\text { Оптимистический } \\
\text { прогноз }\end{array}$ \\
\hline Заработная плата сотрудников, НДФЛ & & & \\
\hline Отчисления с заработной платы & & & \\
\hline Налог на имущество & & & \\
\hline НДС к уплате & & & \\
\hline Транспортный налог & & & \\
\hline НДС & & & \\
\hline Налог на прибыль, 20\% & & & \\
\hline Всего & & & \\
\hline
\end{tabular}

Таблица 6. Прогноз клиентской базы предприятия

\begin{tabular}{|l|c|c|c|}
\hline & $\begin{array}{c}\text { Умеренный } \\
\text { прогноз }\end{array}$ & $\begin{array}{c}\text { Оптимальный } \\
\text { прогно3 }\end{array}$ & $\begin{array}{c}\text { Оптимистический } \\
\text { прогноз }\end{array}$ \\
\hline Поступление по действующим договорам & & & \\
\hline Физические лица & & & \\
\hline Прочие покупатели & & & \\
\hline Поступления от реализации, с НДС & & & \\
\hline
\end{tabular}

деятельности предприятия.

Бюджеты разрабатываются в зависимости от целей, которые ставит руководитель, не имеют какой-либо стандартизированной формы, они создаются в зависимости от объекта бюджета, размера предприятия, целей предприятия, детальной проработки показателей, имеющейся информации и т.п. К этапам формирования бюджетирования на предприятии относятся: разработка финансовой структуры, создание системы показателей, разработка методики оформления бюджетных отчетов, создание регламентов взаимодействия и форм бюджетного контроля.

\section{Библиографический список}

1. ураков Л.П. Рябинина Э.Н. Агатеева Г.Л. Бюджетирование как метод управления финансовыми ресурсами: Учебное пособие.- Чебоксары: Изд-во Чуваш. Ун-та. 2014. - с. 135

2. Шаховская, В.В. Хохлов, О.Г. Кулакова. Бюджетирование: теория и практика: учебное пособие [и др.].- М.: КНОРУС. 2013- с. 400; К вопросу показателей качества строительства как составляющей ценности. Гуськова М.Ф., Стерликов П.Ф., Стерликов Ф.Ф. Вопросы экономики и права. 2015. № 1. С. 86.

3. Пичугина Л. Технология автоматизации бюджетирования на производственных предприятиях//»Финансовая газета». 2013. № 51; Гуськова М.Ф., Стерликов П.Ф., Стерликов Ф.Ф. Диалектика экономического прогресса // Экономические науки. 2006. № 7. С. 154.

4. Бирюлин Д.Ц. Постановка бюджетирования на промышленном предприятии // Финансовый менеджмент. 2014. № 4 